line, ultimately disappear. It is proved that there is no direct connexion between the structure of the discrete bands and the continuous spectrum.

The continuous spectrum mentioned above may certainly be explained by the emission of the excited ${ }^{2} P$ atoms during their collisions with other normal atoms (quasi-molecules). It seems that the emission of the main part of the strong continuous spectrum in the back-ground of the red band system is closely connected with the transitions $1 \Sigma_{u}^{+} \rightarrow 1 \Sigma_{g}^{+}$of the quasi-molecules. Similarly, the continuous spectrum

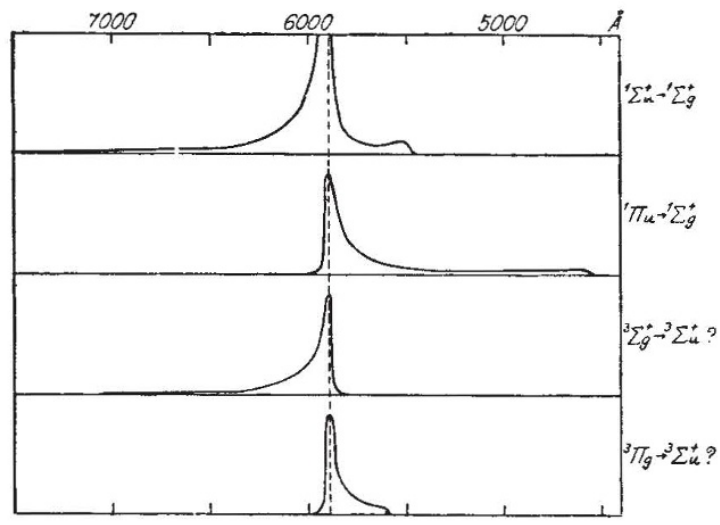

FTG. 1.

in the back-ground of the green band system seems to have an intimate connexion with the latter band system $\left({ }^{1} \pi_{u} \rightarrow{ }^{1} \Sigma_{g}^{+}\right)$. Besides, there is also possible the emission of a continuous spectrum due to the transitions ${ }^{3} \Sigma_{g}^{+} \rightarrow{ }^{3} \Sigma_{u}^{+}$and ${ }^{8} \pi_{g} \rightarrow{ }^{3} \Sigma_{u}^{+}$of the quasi-molecules on the side of the longer wave-lengths of the $D$ lines, or in the vicinity of them (Fig. 1).

The main part of the continuous spectrum emitted from the sodium arc, or from the sodium flame, when the density of sodium vapour is fairly high, has the same distribution of intensity as that obtained in this experiment.

Similar results are obtained in the case of potassium.

$$
\begin{gathered}
\text { Physical Institute, } \\
\text { Sendai, Japan. } \\
\text { Sept. } 24 .
\end{gathered}
$$

\section{Discontinuous Distribution in Plants}

IN NATURE of July 9, p. 58, I gave an account of a genus of bees (Hesperapis) which was found to exist in dry regions of the south-west United States, and again in the dry parts of South Africa. I have just received from the Missouri Botanical Garden a very thorough revision of the genus Menodora, by Julian A. Steyermark. This is a genus of oleaceous plants, found in dry or semi-desert regions, in south. west North America, a large area in Central and southern South America, and a few forms in the Transvaal and adjacent parts of South Africa. Thus except for the South American area, the distribution nearly corresponds with that of Hesperapis.

One of the South African forms, certainly native and frequently collected in the Transvaal, has been supposed to be identical with Menodora heterophylla, which is abundant in Texas, and occurs in the Mexican States of Tamaulipas and Nuevo Leon. Mr.
Steyermark points out that in spite of the great resemblance, the South African plant differs in a num. ber of respects, so that he calls it variety australis. Evidently it should rank as a separate species, Menodora australis, as it cannot be supposed to have any direct genetic connexion with the North American plant. Mr. Steyermark himself calls it "a very striking instance, seemingly, of parallel development". On p. 109, however, he writes : " $M$. heterophylla, occurs with its variety in two widely separated continents, namely, North America and Africa. Since this distribution may be explained by the supposition of the existence of a land-bridge forming a ready means of dispersal for species between the continents, it may be supposed that $M$. heterophylla extended from North America to South Africa over the postulated lost continent, Gondwana, before the end of the Cretaceous."

This seems to me to be wholly fanciful, and had there been any such connexion, is it likely that this species of plants has remained unchanged since the Cretaceous, or that a fow forms crossed over, leaving the mass of the fauna and flora behind? There is no reason to doubt that the genera Menodora and Hesperapis are of great antiquity, and presumably spread to their now remote outposts by way of Asia, but very similar species have evolved independently under similar conditions. Unfortunately xerophytic conditions are not favourable for the preservation of fossil plants and insects, so that we get very little evidence from the rocks concerning the past plant or invertebrate life of dry regions. We do, however, find in the Miocene deposit at Florissant, Colorado, fossil Proteaceæ, a family of plants now especially characteristic of South Africa and Australia, and a species of Nemopteridæ, curious insects with long slender hind wings, known from southern South America and dry regions of the Old World, but to-day wholly lacking in North America.

The distribution and origin of desert life may well attract all students interested in the wider aspects of biology. After visiting desert and semi-desert regions in many parts of the world, one is struck by the extraordinary character of the responses to the environment, producing similar and highly characteristic organisms, often of quite different origin. Judging by the completeness of the adaptations, and the great number of peculiar types, it seems that the South African desert area has some claim to be considered the oldest of them all.

University of Colorado,

T. D. A. Cockerell.

Boulder, Colorado.

Oct. 7 .

\section{Protective Properties of Colloids and their Behaviour} in the Electrolytic Deposition of Metals

Previous observations made by $\mathrm{me}^{1}$ on the mechanical stress in cathode plates during electrolysis of copper sulphate, showed that the effect of gelatin in the solutions is marked at very low concentrations (0.5-1 mgm. per litre). The state of the solution is also of great importance, the stress varying considerably with the age of the solution. This makes it possible to follow the evolution of a solution as a function of time by the electrochemical method.

I have continued my experiments with other colloids: serum albumin, gum arabic, gum tragacanth, and dextrin, in concentrations varying from 1 to $500 \mathrm{mgm}$. per litre. The results show a very

No. 3291, Vol. 130] 